\title{
The 'bio-assay' quality of life might be a better marker of disease activity in acromegalic patients than serum total IGF-I concentrations
}

\author{
Ingrid E Bonapart ${ }^{1}$, Ron van Domburg ${ }^{2}$, Saskia M T H ten Have ${ }^{1}$, Wouter W de Herder ${ }^{1}$, Ruud A M Erdman ${ }^{3}$, \\ Joop A M J L Janssen ${ }^{1}$ and Aart Jan van der Lely ${ }^{1}$ \\ ${ }^{1}$ Departments of Endocrinology, ${ }^{2}$ Biostatistics and ${ }^{3}$ Psychology, Erasmus Medical Centre, University Hospital of Rotterdam, Rotterdam, The Netherlands \\ (Correspondence should be addressed to Aart Jan van der Lely, Department of Internal Medicine, Erasmus MC, 40 Dr Molewaterplein, \\ 3015 GD Rotterdam, The Netherlands; Email: a.vanderlelij@erasmusmc.nl)
}

\begin{abstract}
Objectives: To investigate the quality of life $(\mathrm{QoL})$ in acromegalic patients in relation to biochemical parameters.

Design and methods: Single-center, open label study in 14 acromegalic patients (eight woman and six men, age 33-77 years), with normal serum IGF-I levels during long-term treatment with monthly injections of $20 \mathrm{mg}$ of long-acting octreotide. We investigated which biochemical parameter might reflect optimal QoL, using the SF-36 questionnaire.

Results: We observed that six patients had a low QoL score at baseline in the same range as observed in cancer patients. The other eight patients had a normal QoL. GH, IGF-I nor free IGF-I could discriminate these two subgroups at baseline. After skipping one monthly injection, all six subjects with the low QoL escaped in their free IGF-I concentrations. Also total IGF-I concentrations escaped in four of these six. In the subjects with normal QoL, free IGF-I levels remained normal in all, while total IGF-I levels only escaped in one.

Conclusions: This study tells us that the currently used biochemical criteria for disease control in acromegaly might be sufficient in assessing long-term mortality and morbidity, but they are insufficient in addressing the most important parameter from the patient's perspective - QoL.
\end{abstract}

European Journal of Endocrinology 152 217-224

\section{Introduction}

Physicians involved in the treatment of acromegalic patients know that biochemical control of the disease does not necessarily stop a patient complaining. To address these issues, Sonino and co-workers (1) studied with several symptom questionnaires the effects on quality of life (QoL) of the slow-release somatostatin analogue, lanreotide. Together with a significant decrease in growth hormone $(\mathrm{GH})$ and insulin-like growth factor-I (IGF-I), treatment with lanreotide significantly improved psychological distress, well-being and social fears (1). In a another study on the efficacy of the novel GH receptor antagonist pegvisomant to lower serum IGF-I concentrations, a questionnaire evaluating five clinical signs and symptoms of acromegaly showed significant dose dependent differences from placebo (2). Recently, Webb and co-workers reported the successful development of a disease-specific questionnaire suitable to measure health-related QoL in acromegaly (ACROQOL) (3).

Another QoL measure, the MOS 36-Item Short-Form Health Survey (SF-36), was used to assess patients' perception of the impact of a pituitary adenoma, prior to treatment, on his or her physical and mental functioning in 270 new patients evaluated for pituitary disease at the University of Virginia Pituitary Clinic (4). They clearly found that patients with a pituitary adenoma do have an impaired QoL that should be routinely assessed in conjunction with endocrine and anatomic studies before and after treatment (4).

However, no clear biochemical parameter appears to be available that correlates well with disease activityrelated QoL (5). At the same time, serum GH concentrations and serum total IGF-I levels, but not QoL, are used as parameters to determine dosing of Sandostatin LAR, or any of the available medical therapies for acromegaly (6-9).

As no data from the literature are available that use the patient's own opinion as a parameter for dosing, we designed a double blind study, in which self-assessment of the patient was correlated with the known biochemical disease parameters. We only investigated patients sensitive to long-acting somatostatin receptor agonists (Sandostatin LAR), which meant that IGF-I levels 
were normalized in all these patients during long-term LAR treatment. Sandostatin LAR, a synthetic octapeptide-somatostatin analogue, is a long-acting release formulation of octreotide, in which the drug has been incorporated into microspheres of a biodegradable polymer. It is administered as an intramuscular injection every 4 weeks. The usual starting dose is $20 \mathrm{mg}$, and the dose may be adjusted up to $30 \mathrm{mg}$ if there is insufficient suppression of GH and IGF-I (8-14).

Self-assessment of the patient in this study was obtained with the Medical Outcomes Study (MOS)-36Item Short-Form Health Survey (SF-36). The SF-36 is a multi-purpose, short-form health survey with only 36 questions. It yields an 8-scale profile of functional health and well-being scores as well as psychometrically-based physical and mental health summary measures and a preference-based health utility index. It is a generic measure, as opposed to one that targets a specific age, disease, or treatment group. Accordingly, the SF-36 has proven useful in surveys of general and specific populations, comparing the relative burden of diseases, and in differentiating the health benefits produced by a wide range of different treatments, constructed as an alternative to longer measures included in MOS questionnaires. The MOS is a longitudinal investigation of variations in health status from the point of view of patients with chronic conditions (15). Eight of the most useful scales of the MOS health concepts are included in the SF-36 and presented in Table 1 with the number of items used to score each scale $(16-21)$. The generic nature of the SF-36 allows comparisons to be made of the relative benefit of different treatments, and in this setting, results from clinical studies have largely supported the validity of the SF-36 scales (22).

A 5-point ( $0-8$ rating scale) questionnaire evaluating five clinical symptoms of acromegaly (soft tissue swelling, arthralgia, headache, excessive perspiration and fatigue) (2), was also used in order to measure the frequency and impact of disease-specific symptoms.

\section{Subjects}

Fourteen subjects (eight woman and six men; age 33-77 years) were included in the study (Table 2). Acromegaly was previously diagnosed based on the clinical presentation, GH levels unsuppressed during an oral glucose tolerance test, elevated age- and gender-matched IGF-I levels (and radiological detection of a pituitary tumor). Twelve patients had a macroadenoma of the pituitary gland. Eleven patients were primarily treated with pituitary surgery, followed in ten patients by radiotherapy. Surgery was at least 2 years, with a maximum of 21 years, before the start of the study and radiotherapy was at least 4 years, with a maximum of 21 years, prior to the start of the study.

Before the study all subjects were treated monthly with Sandostatin LAR $20 \mathrm{mg}$, at least 1 year and 3 months, with a maximum of 7 years, and all subjects had total serum IGF-I levels within the normal ageand gender-adjusted range.

Normal anterior pituitary functions (apart from GH secretion) were present in seven patients, of which three woman were receiving primary medical therapy. Panhypopituitarism was present in three patients and deficiency of one or two pituitary axes was present in four patients. All patients were on stable pituitary replacement therapy. None of the subjects had abnormal renal or liver functions or a history of cancer. Seven patients received anti-hypertensive medication, two of which had a history of a transient ischemic attack. Two patients received medication for hyperlipidemia and two other patients received oral anti-hypergycemics medication for type 2 diabetes mellitus.

\section{Methods}

According to their QoL score at baseline, i.e. during long-term $20 \mathrm{mg}$ Sandostatin LAR treatment, patients were stratified into two groups: one group with low QoL $(n=6$; the unhappy patients) and one group

Table 1 Definition of health concepts using the SF-36 questionnaire.

\begin{tabular}{|c|c|c|}
\hline Concepts & No. of items & Definition \\
\hline Physical functioning & 10 & $\begin{array}{l}\text { Extent to which health interferes with a variety of activities, such as } \\
\text { sports, carrying groceries, climbing stairs and walking }\end{array}$ \\
\hline Role limitations due to physical problems & 4 & $\begin{array}{l}\text { Extent to which health interferes with usual daily activities, } \\
\text { such as work, housework, or school }\end{array}$ \\
\hline Role limitations due to emotional problems & 3 & $\begin{array}{l}\text { Extent to which health interferes with usual daily social activities, } \\
\text { for example accomplished less than would like }\end{array}$ \\
\hline Vitality & 4 & Energy or fatigue \\
\hline Social functioning & 2 & $\begin{array}{l}\text { Extent to which health interferes with normal social activities, } \\
\text { such as visiting with friends during the past week }\end{array}$ \\
\hline Bodily pain & 2 & Extent to bodily pain in past week \\
\hline General health perceptions & 6 & Overall rating of current health in general \\
\hline Total score & 36 & \\
\hline
\end{tabular}

Taken from references $20 ; 21 ; 23$. 
Table 2 Patient characteristics of happy vs unhappy acromegalic patients, using the SF-36 QoL questionnaire, while under long-term long-acting octreotide therapy of $20 \mathrm{mg}$, which decreased serum total IGF-I levels down to within the age and sex adjusted normal ranges. Baseline values are scored at the first visit (wk-4). $P$-values denote statistical differences between octreotide sensitive and nonsensitive subjects. Most patients had received more than one type of previous therapy.

\begin{tabular}{lccc}
\hline Characteristic & Happy & Unhappy & P-value \\
\hline No. of patients & 8 & 6 & $03 \pm 4.8$ \\
Age (mean \pm S.E.M. in yr) & $50 \pm 5.2$ & $2 / 4$ & 0.1017 \\
Sex (no. M/F) & $4 / 4$ & $27.3 \pm 1.0$ \\
Body-mass index (mean \pm S.E.M. in kg/m²) & $27.0 \pm 0.7$ & $11.7 \pm 3.4(5-26)$ \\
Duration of disease (mean \pm S.E.M. in yr (range)) & $13.3 \pm 3.5(2-28)$ & $6(100)$ \\
No. of macroadenoma (\%) & $6(75)$ & $5(83)$ \\
Previous therapy no. (\%) & $6(75)$ & $5(83)$ \\
$\quad$ Surgery & $5(63)$ & $4(67)$ \\
Radiotherapy & $1(13)$ & $4(67)$ \\
No. of deficiency SAl (\%) & $3(38)$ & $5(83)$ \\
No. of deficiency SHT (\%) & $1(13)$ & $2(33)$ \\
No. of deficiency SHG (\%) & $0(0)$ & 0.8129 \\
No. of patients with DM (\%) & & 296 \\
\hline
\end{tabular}

SAI, secondary adrenal insufficiency; SHT, secondary hypothyroidism; SHG, secondary hypogonadism; DM, diabetes mellitus (type II); M, male; F, female.

with a normal QoL ( $n=8$; the happy patients) (Fig. 1$)$. After a wash-out period of 4 weeks, so 8 weeks off Sandostatin LAR $20 \mathrm{mg}$ medication, both the happy and unhappy patients received again their monthly $20 \mathrm{mg}$ Sandostatin LAR for 3 months, followed by another wash-out period of 4 weeks. The study ended with another treatment period of 3 months with Sandostatin LAR. Clinical and laboratory assessments were conducted at each visit. Only the happy group of patients was followed during an extra wash-out period of 3 months to investigate their $\mathrm{QoL}$ and serum total

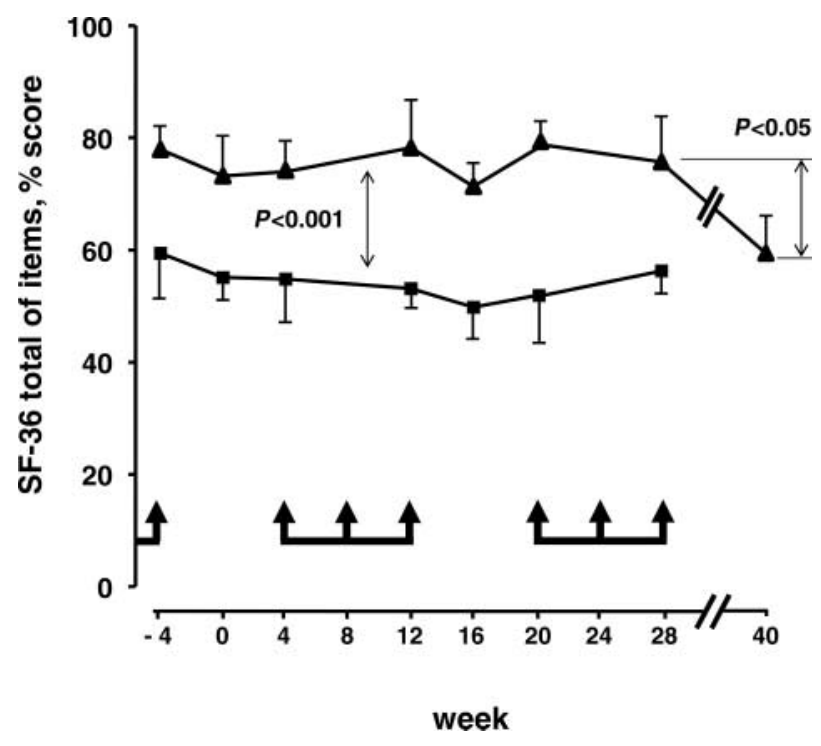

Figure 1 QoL scores (SF-36, total items \pm S.E.M.; \% of score and $100 \%$ indicating optimal QoL, showing the scores of the happy patients with a normal QoL $(\mathbf{\Lambda})$ and unhappy acromegalic patients (ם). The arrows indicate intramuscular injections of $20 \mathrm{mg}$ Sandostatin LAR. The difference between the two groups in QoL was highly significant. The trend of decreasing QoL during the 8 week wash-out of Sandostatin LAR injections in the unhappy group was not significant, while that over the 3 months wash-out was significant.
IGF-I levels without the presence of clinically significant octreotide levels. Routine hematological, serum and urine chemistry parameters were collected, as well as serum GH, total and free serum IGF-I and IGFBP3. At each visit, a Bio-electrical Impedance Analysis (BIA) was performed with the Holtain Body Composition Analyser (Crymych, UK) and all subjects completed the SF-36 Physical and Mental health summary scales and the symptoms questionnaires. Adverse effects were recorded at each visit.

\section{Study procedure}

The study was approved by the Medical Ethics Committee. Subjects were included after their written informed consents were obtained. All blood samples were obtained, after an overnight fast and immediately centrifuged and stored at $-20^{\circ} \mathrm{C}$. BIA for assessment of body composition was performed. Psychometric evaluation was obtained by means of two self-rating scales questionnaires filled in by the patients at each visit.

The SF-36 contains 36 questions measuring both positive and negative health status, of which the validated Dutch translated version was used (23) (Maximal score is 100 , which indicates the most optimal QoL). Item scores were coded and summed into scale scores and transformed into a scale from 0 (worst health) to 100 (best health). The 5-point (0-8 rating scale) symptoms questionnaire evaluates five clinical symptoms of acromegaly (headache, excessive perspiration, arthralgia, fatigue, soft tissue swelling). The scores denote a scale from 0 (no symptoms) to 40 (severe, incapacitating symptoms) (2).

\section{Hormonal assays}

GH (Diagnostic Products Corporation, Los Angeles, USA) and total IGF-I, free IGF-I, IGFBP-3 were assayed by radioimmunoassay (total IGF-I: non-extraction) 
Table 3 Baseline fasting hormone concentrations of happy vs unhappy subjects, using the SF-36 QoL questionnaire, while under longterm long-acting octreotide therapy of $20 \mathrm{mg}$, which decreased serum total IGF-I levels down to within the age and sex adjusted normal ranges.

\begin{tabular}{lcc}
\hline Baseline fasting hormone levels & Happy & Unhappy \\
\hline No. of patients & 8 & 6 \\
Serum GH $(\mathrm{ng} / \mathrm{ml})$ & & 0.85 \\
$\quad$ median & 0.85 & $1.44 \pm 0.6$ \\
$\quad$ mean \pm S.E.M. & $1.05 \pm 0.2$ & $0.4-4.7$ \\
$\quad$ range & $0.4-1.9$ & 22.3 \\
Serum total IGF-I (ng/ml) & 29.2 & $24.6 \pm 3.4$ \\
$\quad$ median & $28.1 \pm 3.1$ & $17.2-39.8$ \\
mean \pm S.E.M. & $9.6-37.5$ & 125.7 \\
range & 92.6 & $181.3 \pm 43.9$ \\
Serum free IGF-I (pmol/l) & $105.4 \pm 20.6$ & $79.5-334.3$ \\
median & $20.8-180$ & 3.80 \\
mean \pm S.E.M. & & $4.37 \pm 0.53$ \\
$\quad$ range & 4.40 & $2.90-6.50$ \\
Serum IGFBP3 (ng/ml) & $4.53 \pm 0.45$ & 0.47 \\
$\quad$ median & $2.60-6.50$ & 0.54 \\
mean \pm S.E.M. & & \\
range &
\end{tabular}

Data are shown as the median, mean \pm S.E.M. and range. GH, growth hormone; IGF-I, insulin-like growth factor I; IGFBP3, insulin-like growth factor binding protein 3.

(Diagnostic Systems Laboratories, Inc.,Webster, Texas, USA). We used the reported results of free-IGF-I as determined by Juul and co-workers (24) as reference values of age- and gender-matched free IGF-I levels. The assay sensitivity was $0.01 \mathrm{ng} / \mathrm{ml}$ for $\mathrm{GH}$, $2.06 \mathrm{ng} / \mathrm{ml}$ for total IGF-I, $0.03 \mathrm{ng} / \mathrm{ml}$ for free IGF-I and $0.5 \mathrm{ng} / \mathrm{ml}$ for IGFBP-3. The intra- and inter-assay coefficients of variation for the low and high points of the curve were $5.3 \%-6.5 \%$ and $5.7 \%-6.1 \%$ for $\mathrm{GH}$, $7.0 \%-3.9 \%$ and $7.4 \%-4.2 \%$ for total IGF-I, $10.3 \%-$ $3.3 \%$ and $7.7 \%-10.7 \%$ for free IGF-I, $1.8-3.9 \%$ and $1.9-0.6 \%$ for IGFBP-3. Age-related reference ranges ( \pm S.D.) for total IGF-I are $100-494(88.3) \mathrm{ng} / \mathrm{ml}$ in patients 30-39 years old, 101-303 (48.3) $\mathrm{ng} / \mathrm{ml}$ in patients 40-49 years old, $78-258(49.3) \mathrm{ng} / \mathrm{ml}$ in patients older than 50 years old, for IGFBP-3 are $1730-7260(900) \mathrm{ng} / \mathrm{ml}(\times 0.035$ for $\mathrm{nmol} / \mathrm{l})$ in patients 30-39 years old 2080-4310 (497) in patients 40-49 years old and 2020-3990 (439) in patients older than 50 years (Table 3).

\section{Data analysis}

Continuous variables, including the primary efficacy end point (decrease from baseline of serum concentrations of GH, IGF-I, IGFBP3 and free IGF-I) were compared with the use of analysis of variance. For statistical analysis, two group (unpaired) student's $t$-test, and unpaired $t$-test with Welch's correction, SPSS 11.0 (SPSS, Inc., Chicago, IL, USA).

For the SF-36 scales, factor analyses were performed to evaluate construct validity in light of what is known about the factor structure of the SF-36 from previous studies $(17,25)$. There were no missing data for the Symptoms questionnaire or for the SF-36.

\section{Results}

Baseline characteristics and hormone concentrations of happy vs unhappy patient groups during long-term treatment with monthly injections of $20 \mathrm{mg}$ of Sandostatin LAR and 4 weeks after the last Sandostatin LAR injection were not significantly different (wk-4; Table 2). Mean age was 56 513 years (minimum 33 and maximum 77 years) and the mean duration of acromegaly was $11 \pm 8$ years (minimum 1 and maximum 28 years). All subjects had normal age- and gender-adjusted total and free IGF-I levels at baseline (Table 3). None of the patients withdrew from the study.

We observed that only the unhappy group (Fig. 1) had free IGF-I concentrations above their age-and gender adjusted normal range within the 8 weeks after the last injection of Sandostatin LAR (so after skipping one injection; Fig. 2). Also they tended to rise above the normal range in their total IGF-I levels (Fig. 3) unlike those of the happy group after skipping one injection of LAR. The total IGF-I levels of the unhappy group seemed to be more stable during wash-out of LAR (Fig. 3). The data obtained from the first wash-out period gave the same information as those obtained from the last wash-out period, as data analyses revealed no extra differences that were significant, nor showed that significance was lost for some parameters after the second wash-out. We therefore only provide the data from the first wash-out period in the following parts of the manuscript. After the study, a third wash-out period of 3 months was performed in those six subjects in whom no rise in total and free IGF-I was observed. After these extra three months without treatment with Sandostatin LAR, all of these patients showed an increase above the normal levels of total IGF-I, which was accompanied 


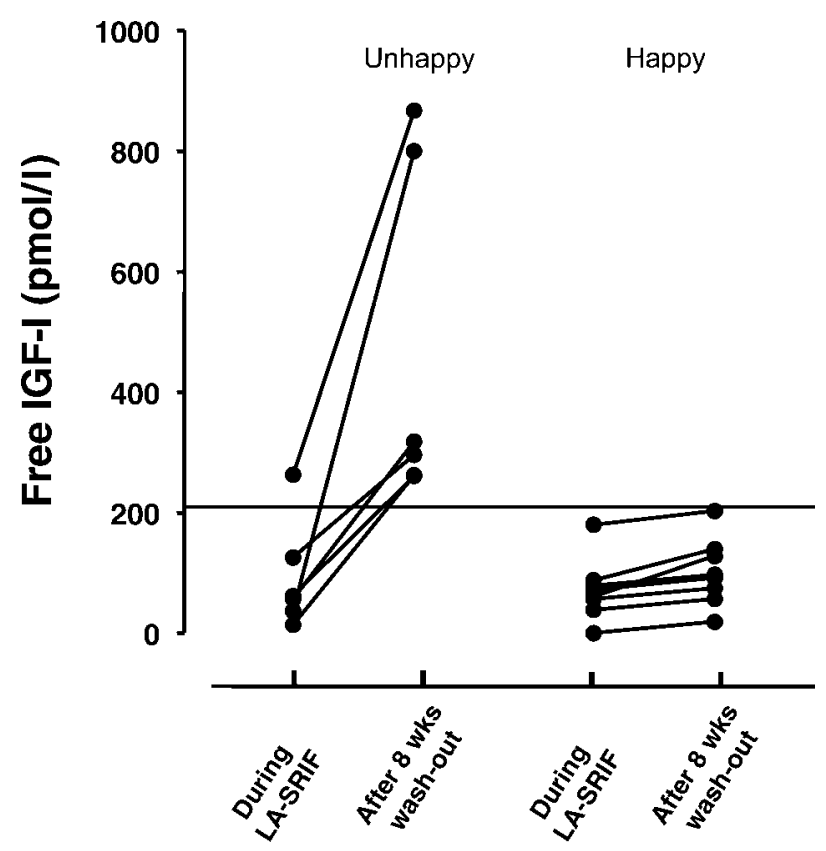

Figure 2 Serum free IGF-I levels (pmol/I) in happy and unhappy acromegalic subjects. Each group shows data on free IGF-I levels during long-term treatment with $20 \mathrm{mg}$ long-acting octreotide and at 8 weeks after the last injection, i.e. after skipping one monthly injection. Note that only the unhappy subjects had serum free IGF-I concentrations above the normal range. (Upper level of normality $205 \mathrm{pmol} / \mathrm{l}$ is indicated as solid line.)

by a recurrence in signs and symptoms of active acromegaly, indicating that they were not cured.

Significantly higher serum GH values at all visits were found in the unhappy subjects compared with the happy subjects when the area under the curves (AUC) over the entire study were used $(P=0.0035)$. When individual data are shown (Fig. 4), this difference in AUC can be explained by the two unhappy subjects who escaped the normal range in their $\mathrm{GH}$ levels during the first wash-out. The same is true for the difference between AUC for the age- and gender adjusted free IGF-I values at all visits between the happy and unhappy group $(P<0.0001 ;$ Fig. 2$)$. However, the patients who did escape normal range in their free IGF-I with the highest wash-out levels were the patients that had the highest $\mathrm{GH}$ levels, both before and after the wash-out. There were no significant differences in total IGF-I $(P=0.99)$.

The difference between the happy and unhappy subjects in QoL in the total SF-36 (mean unhappy QoL score, mean \pm S.E.M. for whole period was $54.3 \pm 1.2$ versus $75.7 \pm 1.1$ for the happy group; $P<0.001$ ) was based on the observed significant differences in 'physical functioning', 'role limitations due to physical functioning' and 'role limitations due to emotional functioning' scores (all $P<0.05$ ). There was also a significantly better score for symptoms of acromegaly for perspiration, arthralgia, and fatigue (all $P<0.05)$, but not in headache and soft tissue swelling

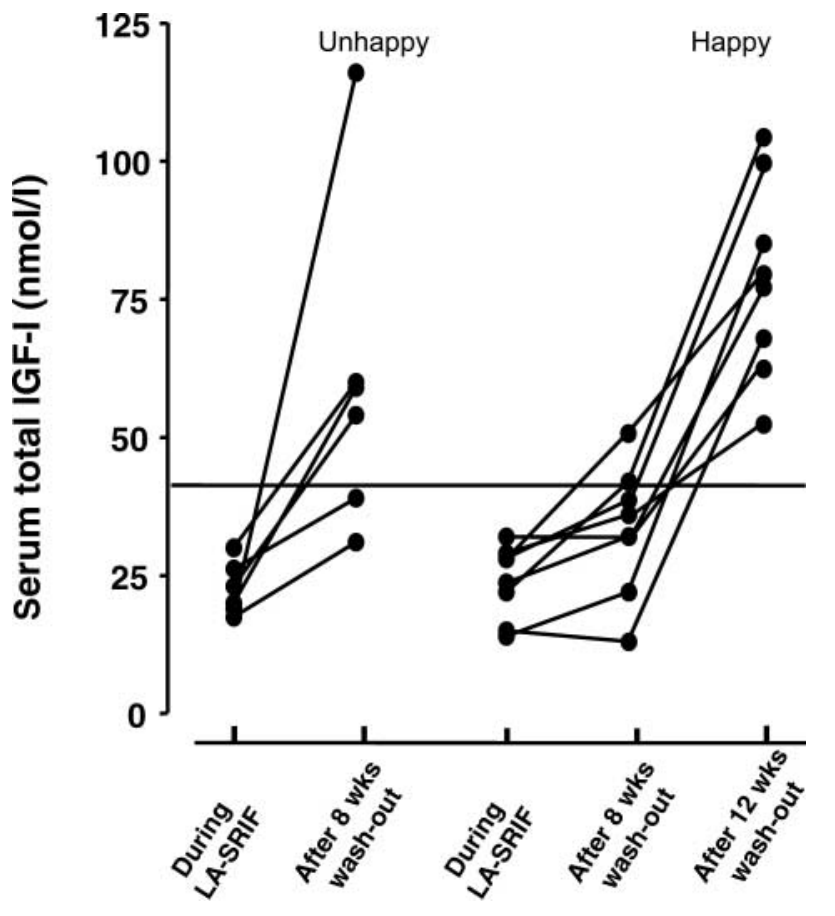

Figure 3 Serum total IGF-I levels (nmol//) in happy and unhappy acromegalic subjects. Each group shows data on total IGF-I levels during long-term treatment with $20 \mathrm{mg}$ long-acting octreotide and at 8 weeks after the last injection, i.e. after skipping one monthly injection. Note that all the unhappy subjects had serum total IGF-I concentrations above the normal range. (Upper level of normality $45 \mathrm{nmol} / \mathrm{I}$ is indicated as solid line.) For the happy group, also the total IGF-I levels after 12 weeks of wash-out are provided, showing that all happy patients did escape after a longer period of time without octreotide therapy.

of the symptoms questionnaire comparing the same subjects.

\section{Safety}

Sandostatin LAR was well tolerated. A mild and transient redness at the injection-site was reported by two patients after receiving one of the Sandostatin LAR injections. Mild gastro-intestinal discomfort was observed by three patients, while dizziness and headache were reported by four patients. No significant changes in safety laboratory were recorded during the study period.

\section{Discussion}

Both GH and IGF-I are reported as factors that might affect long-term morbidity and mortality in acromegalic patients $(9,26-34)$. However, in this study we assess a different parameter in acromegalic patients whom we assume to have an optimized metabolic situation by medical intervention and have decreased IGF-I levels to within what we call the normal range - patients that are 'adequately controlled'. The most inmportant 
message of our study is that in these biochemically controlled patients, we are not able to predict their own most important parameter - QoL. The observed difference in total SF-36 scores that we came across is an important one in the validation study of the SF-36 in the Netherlands, the score of the unhappy acromegalic patients was in the same range as was observed in cancer patients undergoing active anti-neoplastic treatment (23), while the happy acromegalic subjects in our study had the same SF-36 scores as the Dutch control population (23). This suggests that the data of our study indicate that when we use serum total IGF-I levels to define well controlled patients under longterm treatment with at least long-acting somatostatin analogs, we are not able to discriminate between patients that feel so bad that they have the same QoL as cancer patients following chemotherapy regimes, from acromegalic patients that feel good. From the patient's perspective, this implies that physicians are not able to address their complaints in QoL adequately, as they tend to be more or less convinced that they 'cured' these patients, because they brought back their serum IGF-I levels down to within the normal range. Apparently, acromegalic patients are very capable at observing whether or not they are well-controlled, as they can foresee that when they skip one injection of $20 \mathrm{mg}$ of long-acting octreotide, they will escape biochemically in at least their free IGF-I levels and sometimes in their total IGF-I as well. Physicians can apparently not foresee that, as our study shows that happy and unhappy patients have exactly the same total and free IGF-I levels during treatment. Although the difference in QoL might be the result of the difference in GH activity, it is noteworthy that the unhappy patients were more likely to have hypopituitarism (especially hypogonadism and likely infertility and diabetes, although these differences were not significant). Also, cosmetic disfigurement, persistent joint aches etc. may plague even the perfectly 'controlled' patient and impair his/her QoL. This by itself might have affected their perception of well-being.

Our results also give the impression that $\mathrm{GH}$ levels might be more important for the patient's QoL, as mean GH levels in the unhappy group were always higher at any time point, compared with the happy patients. However, this increased mean GH level in the unhappy group was caused by relatively high $\mathrm{GH}$ levels in only two subjects, while the other unhappy subjects had $\mathrm{GH}$ levels that completely overlapped $\mathrm{GH}$ concentrations in the happy group (Fig. 4).

To be sure that the so-called happy patients still had active acromegaly, we took all those subjects who did not have levels outside the normal range biochemically off octreotide medication for 3 months. All of them showed an escape in their total IGF-I and showed a recurrence in signs and symptoms of active acromegaly and a clear reduction in their QoL SF-36 scores, indicating that they indeed were not cured. We have not

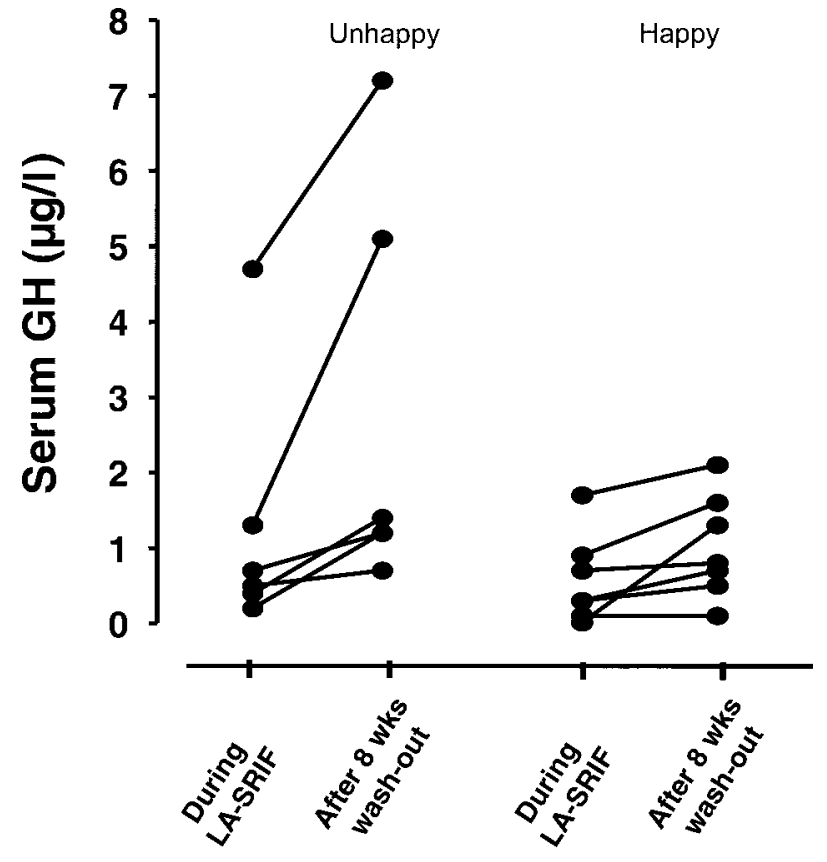

Figure 4 Serum GH levels ( $\mu \mathrm{g} / \mathrm{l})$ in happy and unhappy acromegalic subjects. Each group shows data on GH levels during longterm treatment with $20 \mathrm{mg}$ long-acting octreotide and at 8 weeks after the last injection, so after skipping one monthly injection. Note that only two unhappy subjects show largely increased serum $\mathrm{GH}$ concentrations.

studied potential differences between the happy versus the unhappy subgroup in e.g. octreotide levels or clearance rates of octreotide, as apparently, these potential differences did not result in different serum IGF-I levels under chronic octreotide LAR treatment.

If we may consider QoL as a bio-assay itself, our study indicates that QoL might be superior to serum IGF-I levels in assessing 'poor' control of disease activity according to patients.

In conclusion, we report the outcome of a study in 14 acromegalic patients in whom adequate biochemical control was obtained by long-term long-acting octreotide therapy. Six of these patients had a very low QoL score in the SF-36 questionnaire that was comparable to cancer patients, receiving chemotherapy. The other eight patients had a normal QoL, comparable to the normal population. No biochemical parameter such as GH, IGF-I or free IGF-I could discriminate between these two subgroups. After skipping one injection of the monthly administrations, all six subjects with the low QoL had increased serum free IGF-I concentrations to levels above the normal range. Also total IGF-I concentrations in four of these six increased to levels above the normal range, while in the subjects with normal QoL, serum total and free IGF-I levels remained normal in all but one, who only showed an increase in total IGF-I to just above the normal range.

This study tells us that the currently used biochemical criteria for disease control in acromegaly patients, although potentially sufficient in assessing mortality 
and morbidity in the long run, are insufficient in addressing the most important parameter from the patient's perspective - QoL. In other words, normalization of serum IGF-I concentrations in acromegalic patients by whatever therapy might impress physicians, but not necessarily the patients involved.

\section{Acknowledgements}

We want to thank the staff of the Clinical Research Unit for the excellent care of the patients and their logistical support, and Mr P Uitterlinden for his support in all the laboratory assessments. This study was made possible by an unrestricted grant from Novartis pharma BV, Arnhem, the Netherlands.

\section{References}

1 Sonino N, Scarpa E, Paoletta A, Fallo F \& Boscaro M. Slow-release lanreotide treatment in acromegaly: effects on QoL. Psychotherapy and Psychosomatics 199968 165-167.

2 Trainer PJ, Drake WM, Katznelson L, Freda PU, Herman-Bonert V, van der Lely AJ, Dimaraki EV, Stewart PM, Friend KE, Vance ML, Besser GM, Scarlett JA, Thorner MO, Parkinson C, Klibanski A, Powell JS, Barkan AL, Sheppard MC, Malsonado M, Rose DR, Clemmons DR, Johannsson G, Bengtsson BA, Stavrou S, Kleinberg DL, Cook DM, Phillips LS, Bidlingmaier M, Strasburger CJ, Hackett S, Zib K, Bennett WF \& Davis RJ. Treatment of acromegaly with the growth hormone-receptor antagonist pegvisomant. New England Journal of Medicine $2000 \mathbf{3 4 2}$ 1171-1177.

3 Webb SM, Prieto L, Badia X, Albareda M, Catala M, Gaztambide S, Lucas T, Paramo C, Pico A, Lucas A, Halperin I, Obiols G \& Astorga R. Acromegaly QoL Questionnaire (ACROQOL) a new health-related QoL questionnaire for patients with acromegaly: development and psychometric properties. Clinical Endocrinology Oxford $2002 \mathbf{5 7} 251-258$.

4 Johnson MD, Woodburn CJ \& Vance ML. QoL in patients with a pituitary adenoma. Pituitary 20036 81-87.

5 van der Lely AJ, de Herder WW, Janssen JA \& Lamberts SW. Acromegaly: the significance of serum total and free IGF-I and IGF-binding protein-3 in diagnosis. Journal of Endocrinology 1997155 (Suppl 1 discussion S15-16) S9-13.

6 Melmed S, Jackson I, Kleinberg D \& Klibanski A. Current treatment guidelines for acromegaly. Journal of Clinical Endocrinology and Metabolism $1998 \mathbf{8 3} 2646-2652$.

7 Melmed S. Tight control of growth hormone: an attainable outcome for acromegaly treatment. Journal of Clinical Endocrinology and Metabolism $1998 \mathbf{8 3} 3409-3410$.

8 Sheppard MC. Follow-up of treated acromegaly: similarities and differences in assessing the response to different primary treatment modalities. Growth Hormone and IGF-I Research 200010 (Suppl B) S115-S118.

9 Sheppard MC. Primary medical therapy for acromegaly. Clinical Endocrinology 200358 387-399.

10 Colao A, Ferone D, Marzullo P, Cappabianca P, Cirillo S, Boerlin V, Lancranjan I \& Lombardi G. Long-term effects of depot longacting somatostatin analog octreotide on hormone levels and tumor mass in acromegaly. Journal of Clinical Endocrinology and Metabolism $2001862779-2786$.

11 Bevan JS, Atkin SL, Atkinson AB, Bouloux PM, Hanna F, Harris PE, James RA, McConnell M, Roberts GA, Scanlon MF, Stewart PM, Teasdale E, Turner HE, Wass JA \& Wardlaw JM. Primary medical therapy for acromegaly: an open, prospective, multicenter study of the effects of subcutaneous and intramuscular slow-release octreotide on growth hormone, insulin-like growth factor-I, and tumor size. Journal of Clinical Endocrinology and Metabolism 200287 4554-4563.

12 Cozzi R, Attanasio R, Montini M, Pagani G, Lasio G, Lodrini S, Barausse M, Albizzi M, Dallabonzana D \& Pedroncelli AM. Four-year treatment with octreotide-long-acting repeatable in 110 acromegalic patients: predictive value of short-term results? Journal of Clinical Endocrinology and Metabolism $2003 \mathbf{8 8}$ 3090-3098.

13 Lancranjan I, Bruns C, Grass P, Jaquet P, Jervell J, Kendall-Taylor P, Lamberts SW, Marbach P, Orskov H, Pagani G, Sheppard M \& Simionescu L. Sandostatin LAR: a promising therapeutic tool in the management of acromegalic patients. Metabolism $1996 \mathbf{4 5}$ $67-71$.

14 Stewart PM, Kane KF, Stewart SE, Lancranjan I \& Sheppard MC. Depot long-acting somatostatin analog (Sandostatin-LAR) is an effective treatment for acromegaly. Journal of Clinical Endocrinology and Metabolism 199580 3267-3272.

15 Tarlov AR, Ware JE Jr, Greenfield S, Nelson EC, Perrin E \& Zubkoff M. The Medical Outcomes Study. An application of methods for monitoring the results of medical care. The Journal of the American Medical Association 1989262 925-930.

16 McHorney CA, Ware JE Jr, Lu JF \& Sherbourne CD. The MOS 36item Short-Form Health Survey (SF-36): III. Tests of data quality, scaling assumptions, and reliability across diverse patient groups. Medical Care 199432 40-66.

17 McHorney CA, Ware JE Jr \& Raczek AE. The MOS 36-item ShortForm Health Survey (SF-36): II. Psychometric and clinical tests of validity in measuring physical and mental health constructs. Medical Care 199331 247-263.

18 Ware JE Jr \& Sherbourne CD. The MOS36-item short-form health survey (SF-36). I. Conceptual framework and item selection. Medical Care 199230 473-483.

19 Ware JE Jr, Gandek B, Kosinski M, Aaronson NK, Apolone G, Brazier J, Bullinger M, Kaasa S, Leplege A, Prieto L, Sullivan M \& Thunedborg K. The equivalence of SF-36 summary health scores estimated using standard and country-specific algorithms in 10 countries: results from the IQOLA Project. International QoL Assessment. Journal of Clinical Epidemiology $1998 \mathbf{5 1}$ 1167-1170.

20 Ware JE Jr \& Gandek B. Overview of the SF-36 Health Survey and the International QoL Assessment (IQOLA) Project. Journal of Clinical Epidemiology 199851 903-912.

21 Ware JE Jr \& Gandek B. Methods for testing data quality, scaling assumptions, and reliability: the IQOLA Project approach. International QoL Assessment. Journal of Clinical Epidemiology 1998 51 945-952.

22 Ware JE Jr \& John E Ware Jr on health status and QoL assessment and the next generation of outcomes measurement. Interview by Marcia Stevic and Katie Berry. Journal for Healthcare Quality 1999 21 12-17.

23 Aaronson NK, Muller M, Cohen PD, Essink-Bot ML, Fekkes M, Sanderman R, Sprangers MA, te Velde A \& Verrips E. Translation, validation, and norming of the Dutch language version of the SF36 Health Survey in community and chronic disease populations. Journal of Clinical Epidemiology 199851 1055-1068.

24 Juul A, Holm K, Kastrup KW, Pedersen SA, Michaelsen KF, Scheike T, Rasmussen S, Muller J \& Skakkebaek NE. Free insulin-like growth factor I serum levels in 1430 healthy children and adults, and its diagnostic value in patients suspected of growth hormone deficiency. Journal of Clinical Endocrinology and Metabolism 199782 2497-2502.

25 Ware JE Jr, Kosinski M, Bayliss MS, McHorney CA, Rogers WH \& Raczek A. Comparison of methods for the scoring and statistical analysis of SF-36 health profile and summary measures: summary of results from the Medical Outcomes Study. Medical Care 199533 AS264-AS279.

26 Abosch A, Tyrrell JB, Lamborn KR, Hannegan LT, Applebury CB \& Wilson CB. Transsphenoidal microsurgery for growth hormone-secreting pituitary adenomas: initial outcome and 
long-term results. Journal of Clinical Endocrinology and Metabolism $1998833411-3418$.

27 Ahmed S, Elsheikh M, Stratton IM, Page RC, Adams CB \& Wass JA. Outcome of transphenoidal surgery for acromegaly and its relationship to surgical experience. Clinical Endocrinology 1999 $50561-567$.

28 Arita K, Kurisu K, Tominaga A, Eguchi K, Iida K, Uozumi T \& Kasagi F. Mortality in 154 surgically treated patients with acromegaly - a 10-year follow-up survey. Endocrine Journal 2003 50 163-172.

29 Bates AS, Van't Hoff W, Jones JM \& Clayton RN. An audit of outcome of treatment in acromegaly. Quarterly Journal Of Medicine $199386293-299$.

30 Beauregard C, Truong U, Hardy J \& Serri O. Long-term outcome and mortality after transsphenoidal adenomectomy for acromegaly. Clinical Endocrinology 200358 86-91.

31 Bengtsson BA, Eden S, Ernest I, Oden A \& Sjogren B. Epidemiology and long-term survival in acromegaly. A study of 166 cases diagnosed between 1955 and 1984. Acta Medica Scandinavica $1988223327-335$

32 Biermasz NR, Dulken HV \& Roelfsema F. Postoperative radiotherapy in acromegaly is effective in reducing $\mathrm{GH}$ concentration to safe levels. Clinical Endocrinology 200053 321-327.

33 Orme SM, McNally RJ, Cartwright RA \& Belchetz PE. Mortality and cancer incidence in acromegaly: a retrospective cohort study. United Kingdom Acromegaly Study Group. Journal of Clinical Endocrinology and Metabolism $1998 \mathbf{8 3}$ 2730-2734.

34 Rajasoorya C, Holdaway IM, Wrightson P, Scott DJ \& Ibbertson HK. Determinants of clinical outcome and survival in acromegaly. Clinical Endocrinology 1994 41 95-102.

Received 20 September 2004

Accepted 25 October 2004 